\title{
Post-synthesis treatment of acid-made mesoporous silica materials by ammonia hydrothermal process
}

\author{
Hong-Ping Lin ${ }^{\mathrm{a}, *}$, Chung-Yuan Mou ${ }^{\mathrm{b}}$, Shang-Bin Liu ${ }^{\mathrm{a}}$, Chin-Yuan Tang ${ }^{\mathrm{c}}$, \\ Ching-Yen Lin ${ }^{\mathrm{c}}$ \\ ${ }^{a}$ Institute of Atomic and Molecular Sciences, Academia Sinica, P.O. Box 23-166, Taipei 106, Taiwan, ROC \\ b Department of Chemistry, National Taiwan University, Taipei 106, Taiwan, ROC \\ c Department of Zoology, National Taiwan University, Taipei 106, Taiwan, ROC \\ Received 9 February 2000; accepted 27 August 2000
}

\begin{abstract}
Ammonia hydrothermal treatment provides a novel and convenient method for refining the structural order and pore size uniformity of the acid-made mesoporous silica synthesized from different quaternary ammonium surfactants and acid sources. The post-synthesis treatment provokes transformation of silica wall-surfactant interactions within the mesostructure from the weaker hydrogen bonding $\left(\mathrm{S}^{+} \mathrm{X}^{-} \mathrm{I}^{0}\right)$ to the stronger electrostatic $\left(\mathrm{S}^{+} \mathrm{I}^{-}\right)$interactions. The morphology of the mesoporous silica material remains unchanged after the ammonia hydrothermal treatment at $373 \mathrm{~K}$. Such treatment resulted in an increase in both thermal and hydrothermal stability of the mesostructure. Whereas at higher treatment temperatures $(>373 \mathrm{~K})$, a marked increase in lattice and pore size, as well as an extrusion of silica nanotubes from both sides of the silica ropes, was observed. The extent of such silica nanotubes extrusion and lattice parameters is closely related to the hydrothermal conditions, such as temperature, ammonia concentration and aging time. (c) 2001 Elsevier Science B.V. All rights reserved.
\end{abstract}

Keywords: Mesoporous silica nanotubes; Post-synthesis treatment; Ammonia hydrothermal treatment; Acid synthesis; Morphology

\section{Introduction}

Recent developments of stable, tailor-designed mesoporous silica materials with variable pore sizes and morphologies have expanded into many new potential applications. Well-ordered, thermal

\footnotetext{
${ }^{*}$ Corresponding author. Tel.: +886-2-23668221; fax: +886-223620200.

E-mail address: hplin@gcn.net.tw (H.-P. Lin).
}

stable M41S mesoporous materials have been synthesized from quaternary ammonium surfactants-silicate compositions under alkaline conditions [1,2]. Owing to the strong electrostatic interactions between the silica wall $\left(\mathrm{I}^{-}\right)$and the surfactant $\left(\mathrm{S}^{+}\right)$, these materials normally exhibit a good thermal stability especially after post-synthesis hydrothermal treatments. As a result, the mesoporous materials synthesized via the alkaline route are also less feasible in morphology tailoring. They often exhibit as micrometer-sized particulate morphology and hence limit their applications, for example, in membrane fabrication. Nonetheless, 
some MCM-41 materials with tubular or spherical morphologies have been successfully synthesized [3-6].

On the other hand, the mesoporous materials synthesized via acidic route are more feasible in morphology tailoring. Stucky and coworkers [7] pioneered the acid synthesis of the materials from quaternary ammonium surfactant-TEOS components. The feasibility of the morphology tailoring thus arises from the weaker surfactant/silicate interactions $\left(\mathrm{S}^{+} \mathbf{X}^{-} \mathbf{I}^{+}\right)$during synthesis. Much exotic morphology have been found for the mesoporous silica using acid synthesis including film, hollow spheres, fibers, hollow helicoids and gyroids [817]. Such acid synthesis has also lead to other meso-phase structure (e.g., SBA-n) [18-20]. However, the drawback of the acid-made mesoporous materials is that they are normally less stable, thermally and hydrothermally, than those synthesized via the alkaline route [21]. The methodology development of acid-synthesized mesoporous silica with good structural and morphology stability is thus highly desirable.

Recently, we introduced a post-synthesis ammonia hydrothermal treatment to improve the order and stability of the acid-made mesoporous silica while preserving the original morphology $[21,22]$. The key determining factors involved in such post-synthesis treatment include hydrothermal temperature, concentration of ammonia aqueous solution and aging time. In this work, we discuss the detailed effects of post-synthesis treatment on the enhancement of structural stability, the variations in pore size, morphology preservation, and silica nanotubes formation.

\section{Experimental}

\subsection{Material synthesis}

The acid-made mesoporous silica materials were prepared by the procedure previously reported [10]. Quaternary ammonium surfactants $\mathrm{C}_{n}$ TMAX $(n=14-18 ; \mathrm{X}=\mathrm{Cl}$ or $\mathrm{Br}$; Tokyo Chemical Industry, 98\%), tetraethyl orthosilicate (TEOS; Acrôs, 98\%) and acid sources (HX, such as $\mathrm{HNO}_{3}, \mathrm{HCl}, \mathrm{HBr}$ and $\mathrm{H}_{2} \mathrm{SO}_{4}$; Acrôs) were thoroughly mixed with water under stirring condition at $298-313 \mathrm{~K}$. The final molar gel composition is: 1 surfactant: (3.0-25.0) TEOS: (5.0-40.0) HX: (500-3000) $\mathrm{H}_{2} \mathrm{O}$. It is noted that, in this context, the gel was allowed to age for $24 \mathrm{~h}$ instead of two days, as used in the previous study $[21,22]$. The product was filtered and washed with deionized water and dried at $373 \mathrm{~K}$.

For samples subjected to further ammonia hydrothermal treatment, $1.0 \mathrm{~g}$ dried sample was added into $50.0 \mathrm{~g}(2.0-0.2 \mathrm{M}) \mathrm{NH}_{4} \mathrm{OH}$ aqueous solution and sealed in an autoclaved, then heated in an oven at $373-423 \mathrm{~K}$ for $1-10$ days. As a result, a $\mathrm{pH}$ value of $\approx 10.2-11.2$ is observed. The final product was filtered and again washed thoroughly with deionized water and dried. Typically, samples were calcined in air at $833 \mathrm{~K}$ for $6 \mathrm{~h}$ to remove the organic structure directing agents.

\subsection{Characterization methods}

X-ray powder diffraction (XRD) data were collected on a Scintag X1 diffractometer using $\mathrm{CuK}_{\alpha}$ radiation $(\lambda=0.154 \mathrm{~nm})$. The $\mathrm{N}_{2}$ adsorption-desorption isotherms were obtained at $77 \mathrm{~K}$ on a Micromeritics ASAP 2010 apparatus. Typically, sample was degassed at $523 \mathrm{~K}$ for $6 \mathrm{~h}$ prior to the analysis. Scanning electron microscopy (SEM; Hitachi S-800) was operated at an accelerating voltage of $20 \mathrm{keV}$. Bulk mesoporous materials were probed by transmission electron microscope (TEM; Hitachi 7100) operating at a voltage of 100 $\mathrm{keV}$. Elemental Analysis was performed on a Perkin-Elmer 2400 apparatus and the FTIR spectra were taken on Perkin-Elmer 1600. Solid-state ${ }^{29} \mathrm{Si}$ magic-angle-spinning (MAS) NMR spectra were recorded at room temperature on a Bruker MSL300 spectrometer using a recycle delay of $400 \mathrm{~s}$ and a spinning frequency of $4 \mathrm{kHz}$.

\section{Results and discussion}

\subsection{Hydrothermal and thermal stability}

The effects of post-synthesis ammonia hydrothermal treatment on the structural order and 

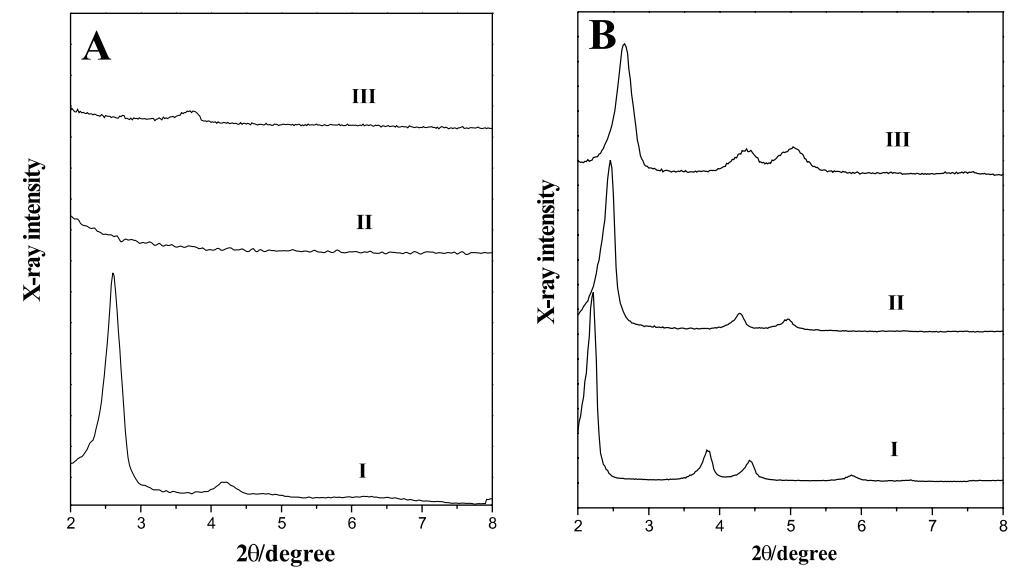

Fig. 1. The XRD patterns of the mesoporous silica synthesized from $\mathrm{C}_{16}$ TMAB-TEOS- $\mathrm{HNO}_{3}-\mathrm{H}_{2} \mathrm{O}$ compositions (A) without and (B) with the ammonia hydrothermal treatment. Samples were prepared by the following procedures: (I) calcination in air at $833 \mathrm{~K}$; $6 \mathrm{~h}$; (II) sample I is subjected to hydrothermal treatment under boiling water for $12 \mathrm{~h}$; (III) sample I is further calcined in air at $1173 \mathrm{~K}$ for $6 \mathrm{~h}$.

Table 1

Physical properties of the calcined mesoporous materials synthesized from $\mathrm{C}_{n} \mathrm{TMAX}(n=14-18 ; \mathrm{X}=\mathrm{Cl}, \mathrm{B})-\mathrm{TEOS}-\mathrm{HX}(\mathrm{X}=\mathrm{Cl}, \mathrm{Br}$, $\left.\mathrm{NO}_{3}, \mathrm{~S}_{1 / 2} \mathrm{O}_{2}\right)-\mathrm{H}_{2} \mathrm{O}$ compositions before and after ammonia hydrothermal treatment at $373 \mathrm{~K}$

\begin{tabular}{|c|c|c|c|c|c|}
\hline \multirow[t]{2}{*}{ Surfactant template } & \multirow[t]{2}{*}{ Acid source } & \multicolumn{2}{|c|}{ Acid-made sample } & \multicolumn{2}{|c|}{ Ammonia treatment } \\
\hline & & $d_{100}{ }^{\mathrm{a}}$ & Pore size ${ }^{\mathrm{b}}$ & $d_{100^{\mathrm{a}}}$ & Pore size ${ }^{b}$ \\
\hline $\mathrm{C}_{16} \mathrm{TMAB}$ & $\mathrm{H}_{2} \mathrm{SO}_{4}$ & $3.36(3.76)$ & $2.26(1.00)$ & $3.92(4.06)$ & $2.62(0.12)$ \\
\hline $\mathrm{C}_{16}$ TMAB & $\mathrm{HCl}$ & $3.28(3.73)$ & $2.30(0.95)$ & $3.88(4.01)$ & $2.59(0.11)$ \\
\hline $\mathrm{C}_{16} \mathrm{TMAB}$ & $\mathrm{HBr}$ & $3.46(3.82)$ & $2.43(0.90)$ & $3.90(4.03)$ & $2.60(0.10)$ \\
\hline $\mathrm{C}_{16} \mathrm{TMAB}$ & $\mathrm{HNO}_{3}$ & $3.60(3.95)$ & $2.45(1.00)$ & $3.95(4.05)$ & $2.63(0.10)$ \\
\hline $\mathrm{C}_{18} \mathrm{TMACl}$ & $\mathrm{HNO}_{3}$ & $4.10(4.46)$ & $2.85(1.10)$ & $4.20(4.38)$ & $2.96(0.12)$ \\
\hline $\mathrm{C}_{14} \mathrm{TMAB}$ & $\mathrm{HNO}_{3}$ & $3.16(3.58)$ & $2.20(0.90)$ & $3.72(3.86)$ & $2.46(0.11)$ \\
\hline
\end{tabular}

\footnotetext{
${ }^{a}$ Obtained from the XRD results in $\mathrm{nm}$. Values in parentheses from the as-synthesized (i.e. uncalcined) mesoporous materials.

${ }^{\mathrm{b}}$ As determined by the BJH method from nitrogen adsorption data, in $\mathrm{nm}$. The values in parentheses indicate the pore distribution line width in FWHM.
}

stability of the acid-made mesoporous silica can be deduced from the XRD profiles (Fig. 1) and nitrogen adsorption data (Table 1). In the absence of the ammonia hydrothermal treatment, the hexagonal structural order collapses when the calcined sample is subjected to either hydrothermal treatment under boiling water or further high temperature $(1173 \mathrm{~K})$ calcination in air, as shown in Fig. 1A. One also finds that the lattice shrinkage, induced from calcination at $833 \mathrm{~K}$, is larger in acidmade mesoporous materials (without ammonia hydrothermal treatment, $\sim 0.4 \mathrm{~nm}$ ) than the ammonia-treated ones $(\sim 0.1 \mathrm{~nm})$. This is in line with the notion that the acid-made mesoporous materials are, in general, less stable than those synthesized via the alkaline route [21]. On the other hand, for the ammonia-treated samples, additional higher order peaks are evident even under severe thermal and hydrothermal tests (Fig. 1B). The ammonia hydrothermal treatment is thus effective in improving the hexagonal order of the mesostructure.

The results obtained from the $\mathrm{N}_{2}$ adsorptiondesorption isotherms are also in agreement with the above observations: a steeper capillary condensation was found (not shown) for samples 


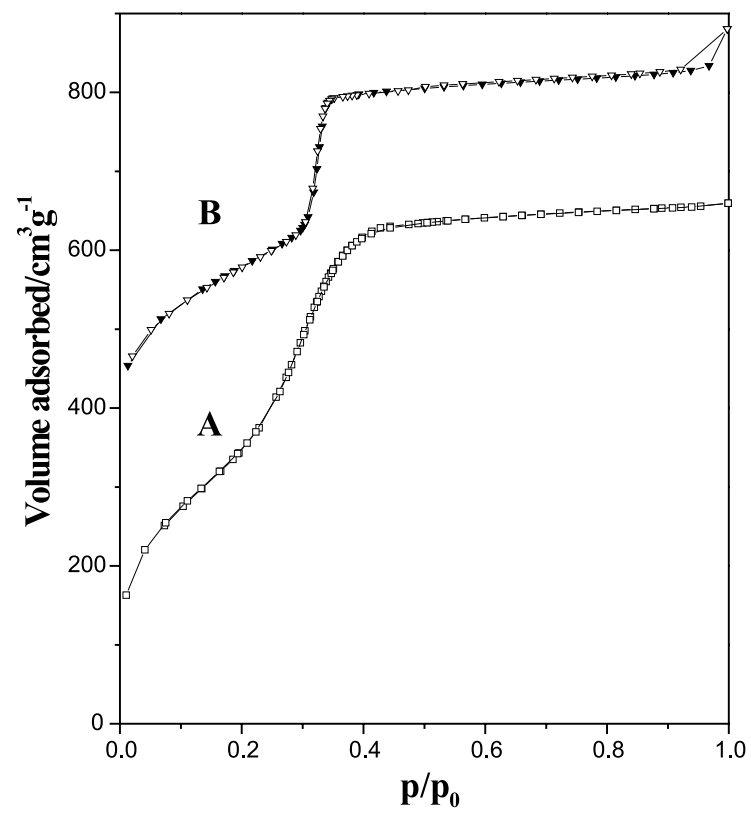

Fig. 2. The $\mathrm{N}_{2}$ adsorption-desorption isotherms of the calcined mesoporous silica obtained from $\mathrm{C}_{16}$ TMAB-TEOS- $\mathrm{HNO}_{3}-$ $\mathrm{H}_{2} \mathrm{O}$ compositions (A) without and (B) with the ammonia hydrothermal treatment (amount adsorbed for isotherm (B) was incremented by $\left.300 \mathrm{~cm}^{3} \mathrm{STP}\right)$.

with ammonia hydrothermal treatment (occurs at $\approx p / p_{0}=0.33-0.35$; Fig. $2 \mathrm{~A}$ ), as compared to the acid-made samples (occur at $\approx p / p_{0}=0.23-0.38$; Fig. 2B). As a result, BJH pore size distribution analyses indicate that the ammonia-treated sample generally has a greater pore size (Table 1) with narrower full-width half-maximum pore-width $($ FWHM $\sim 0.1 \mathrm{~nm})$ than the acid-made sample (FWHM $\sim 1.0 \mathrm{~nm}$ ).

The effects of varying synthesis compositions, namely by using different surfactant templates and/ or acid sources have also been examined, the results are summarized in Table 1. Typically, the BET surface areas of the samples are $\approx 1000-1200 \mathrm{~m}^{2} / \mathrm{g}$. It is worth pointing out that a careful control of the $\mathrm{pH}$ value at $\approx 10.2-11.2$ is crucial during the postsynthesis hydrothermal treatment. Owing to buffer ability of the $\mathrm{NH}_{4} \mathrm{OH}$ solution, it is thus a better agent for the fine control of the $\mathrm{pH}$ value of the reaction composition around 10 . Using a strong base solution (e.g., $\mathrm{NaOH}$ or $\mathrm{KOH}$ ) with the same

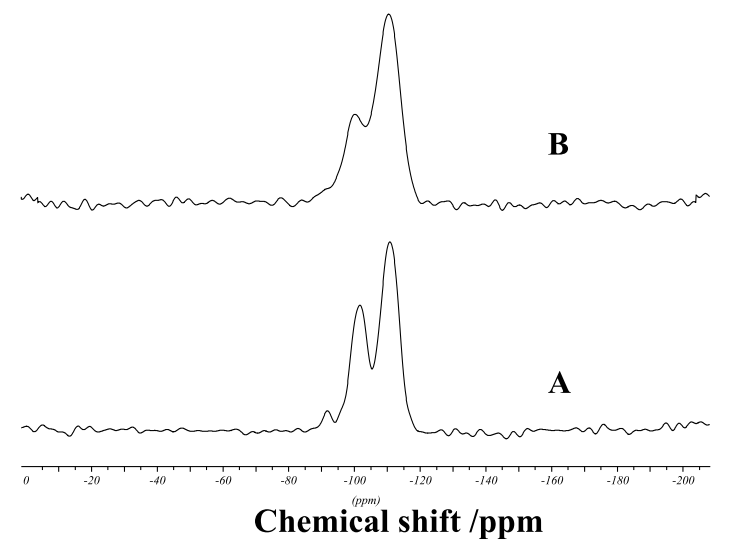

Fig. 3. ${ }^{29} \mathrm{Si}$ MAS NMR spectra of the as-synthesized mesoporous silica synthesized from $\mathrm{C}_{16}$ TMAB-TEOS- $\mathrm{HNO}_{3}-\mathrm{H}_{2} \mathrm{O}$ compositions (A) without and (B) with the ammonia hydrothermal treatment.

initial $\mathrm{pH}$ value in post-synthesis treatment, however, rapidly changes its $\mathrm{pH}$ value and lost the buffering upon hydrothermal treatment. And one gets poor order in the product. A continuous cumbersome and delicate titration procedure at room temperature is necessary for adjusting to the desired $\mathrm{pH}$ value before hydrothermal reaction.

The ${ }^{29}$ Si MAS NMR spectra of the as-synthesized mesoporous materials with and without ammonia hydrothermal treatment are depicted in Fig. 3. It is well known that hydrothermal treatment favor further $\mathrm{Si}-\mathrm{O}-\mathrm{Si}$ bond condensation. The decrease in the $\mathrm{Q}^{3}\left(\mathrm{HOSi}(\mathrm{SiO})_{3}\right)$ resonance peak intensity (at $\approx-100 \mathrm{ppm}$ ) for the ammoniatreated sample (Fig. 2B) therefore indicates that the silica framework further condenses during the ammonia hydrothermal treatment. Such silica condensation favors the formation of mesoporous materials with thicker walls, which can be estimated from by: wall thickness $=\left[2 / \sqrt{ } 3 d_{100}\right.$-pore diameter]. Indeed, the ammonia-treated samples possess a slightly thicker wall $(\approx 1.7 \mathrm{~nm})$ than the acid-made samples $(\approx 1.2 \mathrm{~nm})$.

Thus, the ammonia hydrothermal treatment serves to improve the structural ordering of the acid-synthesized mesoporous silica and hence enhance the thermal and hydrothermal stability with a slight increase in the average pore size. 


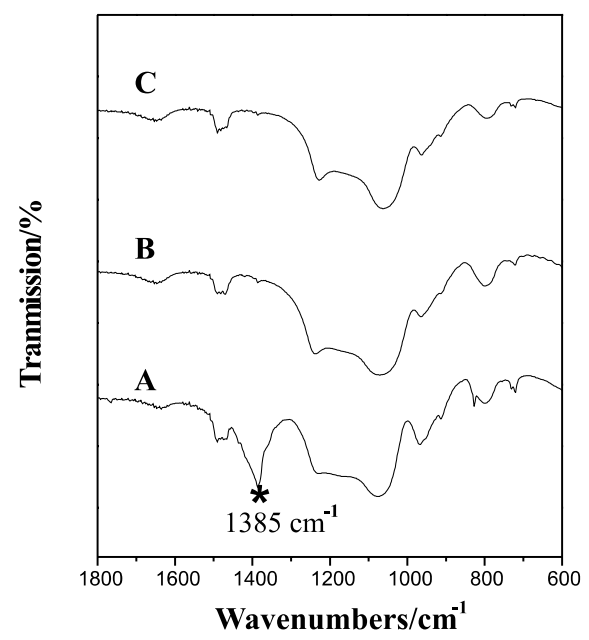

Fig. 4. IR spectra of the as-synthesized mesoporous silica obtained from $\mathrm{C}_{16}$ TMAB-TEOS- $\mathrm{HNO}_{3}-\mathrm{H}_{2} \mathrm{O}$ compositions, (A) before ammonia hydrothermal treatment and (B) after ammonia hydrothermal treatment, as compared to (C) alkaline-made sample prepared from $\mathrm{C}_{16}$ TMAB-sodium silicate- $\mathrm{H}_{2} \mathrm{O}$ compositions.

\subsection{Transformation of silica-surfactant interactions}

As described above, the ammonia hydrothermal treatment is capable of improving the structural order of the acid-made mesoporous materials. The detailed mechanism that provokes such stability enhancement deserves further investigation. It is noted that an additional IR absorption band at $1385 \mathrm{~cm}^{-1}$ appears for the as-synthesized acidmade sample (Fig. 4A) [23]. Such band is not visible for the as-synthesized ammonia-treated (Fig. 4B) or alkaline-made samples (Fig. 4C), which both exhibit nearly identical IR spectrum. This absorption band arises from the presence of nitrate (i.e., $\mathrm{NO}_{3}^{-}$counterion) in the silica-nitrate$\mathrm{C}_{16}$ TMA complex. Further elemental analyses also indicate an excessive amount of nitrogen in the acid-made sample alone (Table 2). While similar elemental analysis data were observed for the other two samples. The elemental analysis data are therefore complementary to the IR results and together provide a qualitative and quantitative description of the transformation of silica-surfactant interactions. It is estimated that the ratio of $\left[\mathrm{NO}_{3}^{-}\right] /[$surfactant] in acid-made mesoporous ma-
Table 2

Comparison of elemental analysis data of as-synthesized mesoporous materials prepared with different synthetic processes

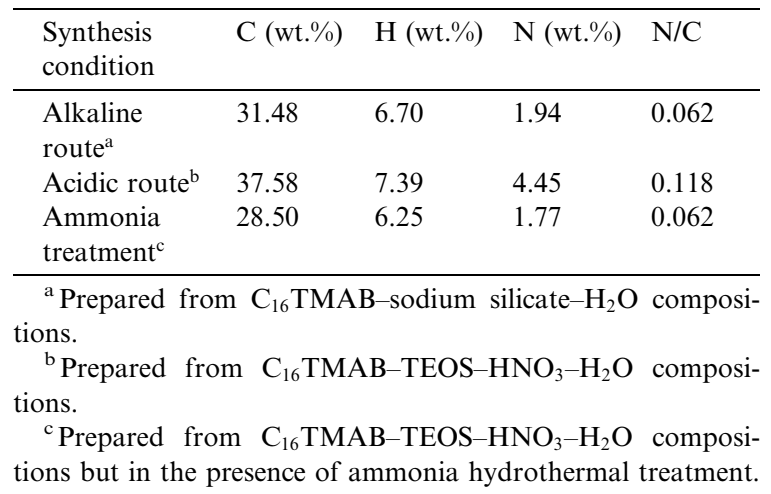

terials is close to 1 . The above results therefore indicate that the nitrate counterions that exist in the acid-made sample were completely removed during the ammonia hydrothermal treatment at $373 \mathrm{~K}$.

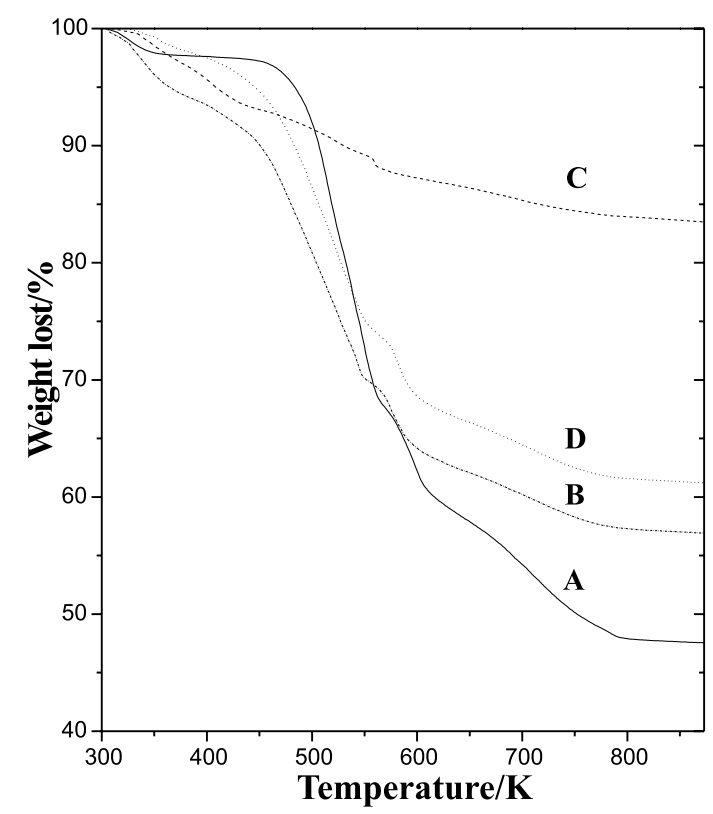

Fig. 5. Effects of ethanol extraction on the TGA thermograms of the as-synthesized mesoporous silica obtained from $\mathrm{C}_{16}$ TMAB-TEOS- $\mathrm{HNO}_{3}-\mathrm{H}_{2} \mathrm{O}$ compositions. The as-synthesized samples were obtained (A) without and (B) with ammonia hydrothermal treatment, both in the absence of ethanol extraction. Samples (C) and (D) were obtained directly from samples (A) and (B), respectively, but under further ethanol extraction process at $323 \mathrm{~K}$ for $5 \mathrm{~h}$. 
To further support this view of transformation of interactions between the silica framework and surfactant templates, the as-synthesized samples (i.e., samples with and without ammonia hydrothermal treatment) were immersed into ethanol at $323 \mathrm{~K}$ for $5 \mathrm{~h}$ with the intention to extract the surfactants from the acid-made samples. Fig. 5 displays the TGA thermograms of the respective samples with and without ethanol extraction. It is estimated that $\approx 85 \%$ of the surfactants exist in the acid-made sample can be facilely extracted. In contrast, the surfactants in the ammonia-treated sample are nearly completely resistant to ethanol extraction.

The above experimental results thus enable us to lay out a schematic mechanistic equilibrium to describe the transformation of interactions between the surfactant, counterion and silica during ammonia hydrothermal treatment as in Scheme 1.

The strong electrostatic interactions provoked by the ammonia hydrothermal treatment thus effectively prevent the extraction of surfactant from the mesostructure (i.e. pore channels) and, in return, resulted in a reorganization of silica and surfactants to form well-ordered, stable mesostructure. We also further examined the effects of hydrothermal conditions, namely the temperature, ammonia concentration and aging time on the pore size and wall thickness of the mesostructure (vide infra).

\subsection{Variations of hydrothermal conditions}

\subsubsection{Temperature effect}

The effect of temperature during ammonia hydrothermal treatment on the structural characteristics, namely lattice and pore size of the acid- made mesoporous silica was examined. The results obtained from the $\mathrm{C}_{16}$ TMAB-TEOS- $\mathrm{HNO}_{3}-\mathrm{H}_{2} \mathrm{O}$ system are depicted in Fig. 6. At constant aging time (two days) and the ammonia concentration $\left(\mathrm{NH}_{4} \mathrm{OH}=1.0 \mathrm{M}\right)$, the $d_{100}$-spacing was found to increase linearly with hydrothermal temperature. Whereas a marked increase in pore size occurs only at elevated temperature ( $>373 \mathrm{~K})$. It is noted that a marked increase in pore size and lattice expansion was also found for the alkaline-made MCM-41 at high hydrothermal temperature $(>373$ K) [24-28].

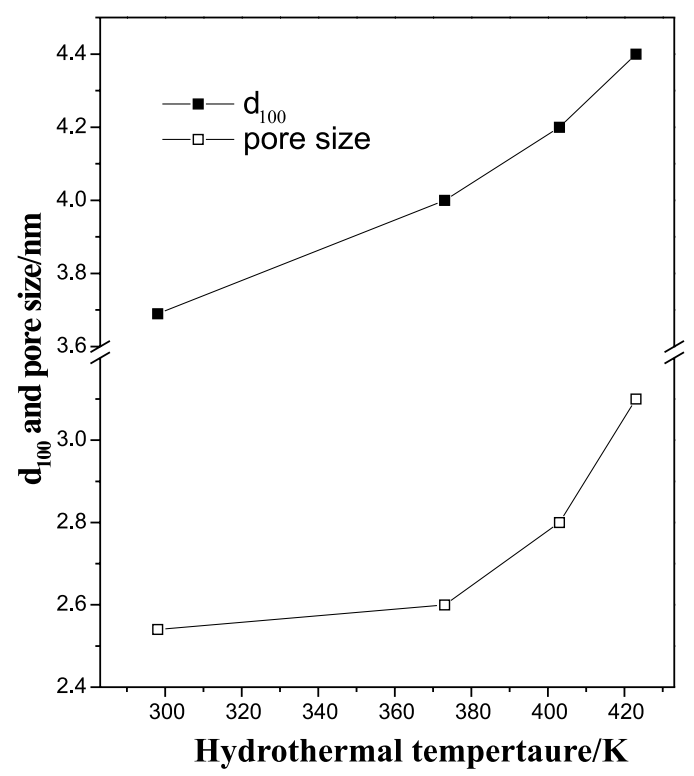

Fig. 6. The effect of ammonia hydrothermal temperature on the $d_{100}$ value and pore diameter of the calcined mesoporous materials prepared from $\mathrm{C}_{16}$ TMAB-TEOS- $\mathrm{HNO}_{3}-\mathrm{H}_{2} \mathrm{O}$ compositions. The aging time (two days) and the ammonia concentration $\left(\left[\mathrm{NH}_{4} \mathrm{OH}\right]=1.0 \mathrm{M}\right)$ were kept constant during the hydrothermal treatment.

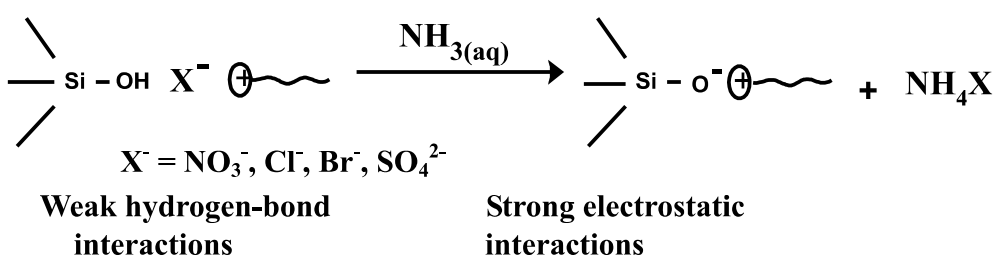

Scheme 1. 


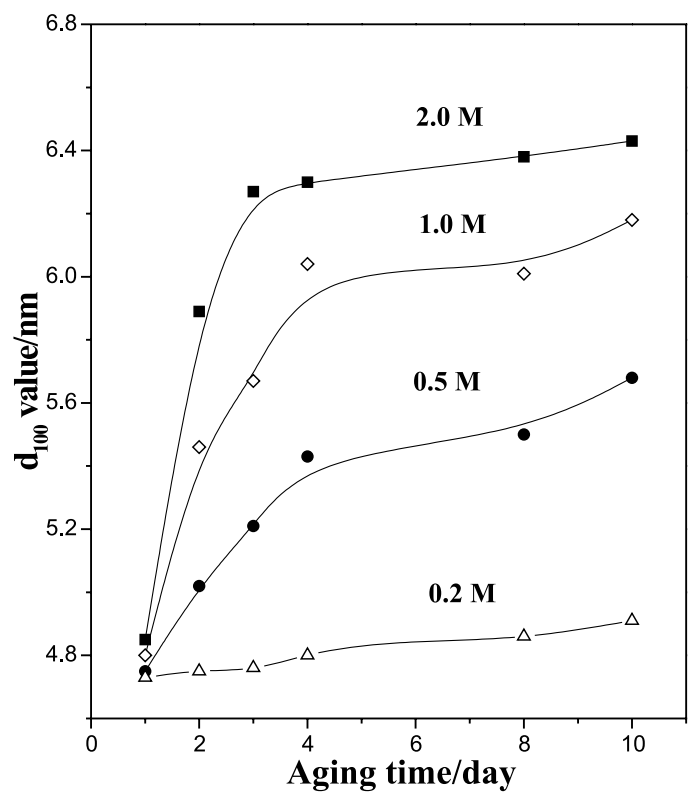

Fig. 7. The effect of aging time and ammonia concentration on the $d_{100}$ value of calcined the mesoporous materials prepared from $\mathrm{C}_{18}$ TMACl-TEOS- $\mathrm{HNO}_{3}-\mathrm{H}_{2} \mathrm{O}$ compositions. The temperature was kept constant during the hydrothermal treatment at $423 \mathrm{~K}$.

\subsubsection{Effects of ammonia concentration and aging time}

The effects of ammonia concentration and aging time during the hydrothermal treatment on the structural characteristics were also examined. The results obtained from mesoporous materials prepared from $\mathrm{C}_{18}$ TMACl-TEOS- $\mathrm{HNO}_{3}-\mathrm{H}_{2} \mathrm{O}$ compositions at constant hydrothermal temperature (423 K) are shown in Fig. 7. In general, for constant ammonia concentration and hydrothermal temperature, a sharp increase in $d_{100}$-spacing can be found for an aging time of two to three days. The effect is more pronounced when the ammonia concentration exceeds $0.5 \mathrm{M}$. A more gradual increase in $d$-spacing occurs when the system is subjected to prolonged aging ( $>3$ days). For example, for an ammonia concentration of $2.0 \mathrm{M}$ (see Fig. 7), the observed $d_{100}$-spacings variation curve nearly plateau when aging time $>3$ days. Moreover, at constant hydrothermal temperature and aging time, an increase in lattice expansion with ammonia concentration is found. Detailed pore size analyses confirmed that the increase in pore size is parallel to the lattice expansion for each sample. Similar behavior was also found in the other acid-made mesoporous materials prepared from different quaternary ammonium surfactants and acid sources.

The observed effects of variations of hydrothermal conditions on lattice parameters during ammonia hydrothermal treatment can be correlated with the equilibrium silicate/surfactant interaction transformation scheme proposed in Eq. (1) (vide supra). Clearly, at higher ammonia concentration, the ammonia-driven reaction equilibrium, which favors silica condensation would shift toward the right-hand side of Eq. (1). In this case, a stronger surfactant-silica interaction is expected and hence most of the surfactant molecules are retained within the mesoporous channels.

The origin of such pore expansion effect, thus far, has been an issue under debate. Sayari and coworkers [24] proposed that the lattice expansion is a consequence of thermal decomposition of surfactants yielding neutral, solubilizing species, such as dimethylhexadecylamine (DMHA) and thus resulted in the pore expansion. Ozin and coworkers [25], on the other hand, advocated that such effect is mainly due to the penetration of water. While the results obtained in the present study are still inadequate to provide firm evidences toward either of the above proposed mechanism. Nonetheless, it is worth pointing out that the retaining of the surfactant molecules inside the channel after the ammonia treatment, while resulting the lattice expansion, is in line with both of the proposed mechanisms. In heating acid-made surfactant/silica composite in water, as more of the surfactant molecules are leached out, the silica wall would tend to collapse inward. In contrast, the expansion of the lattice after ammonia treatment is evidently resulted from the ability of retaining the surfactant within the mesoporous channels at higher temperature $\left(150^{\circ} \mathrm{C}\right)$. Ionic surfactant at high temperature could either decompose thus generate neutral solubilizing molecules such as DMHA or becomes more water compatible to let the in flow of water inside the channels. Either of the above two would lead to the expansion of the 
pore. Under basic condition the Hoffmann degradation to generate amine could in principle be more enhanced. However, we do not know yet whether it is the major cause of pore expansion. The same question exists for the high temperature pore expansion of base-made MCM-41. Further investigation is needed to clarify this important issue.

\subsection{Morphology preservation and silica nanotubes formation}

It is expected that variation in the morphology of the mesoporous silica should be accompanied by a large-scale rearrangement of the nanochannels. While such effect was overlooked in our report on the methodology of ammonia hydrothermal treatment on acid-made mesoporous silica [21]. In the SEM micrographs of the millimetersized silica ropes (Fig. 8A and B), it is obvious that the rope morphology still preserves after ammonia hydrothermal treatment at $373 \mathrm{~K}$, and the silica ropes consist of bundles of micrometer-sized silica fibers. This hierarchical order is almost the same as that without hydrothermal treatment. So, this modest hydrothermal treatment temperature is thus a suitable condition for the enhancement of structural stability of the mesoporous silica while preserving its original morphology.

As described earlier (Fig. 6), the pore size of the mesoporous silica remains practically unchanged when the sample is subjected to ammonia hydrothermal treatment below $373 \mathrm{~K}$, as demonstrated, and the ends of silica fibers are smooth (Fig. 8C). However, upon increasing the hydrothermal temperature $(>373 \mathrm{~K})$ during the ammonia treatment, the subtle morphology changes were observed for mesoporous silica with hierarchical morphology (e.g., gyroids and the ropes), and extrusion of some silica nanotubes on the external cross-sectional surface was observed. Moreover, the extent of such silica extrusion increases with increasing hydrothermal temperature, as shown in Fig. 8D and E. The TEM micrograph (Fig. 8F) of these silica nanotubes shows the structural as analogous to liquid crystal disclination defect of single $+\pi$ [29-31]. Presumably, the formation of the silica nanotubes should be caused by the surfactant
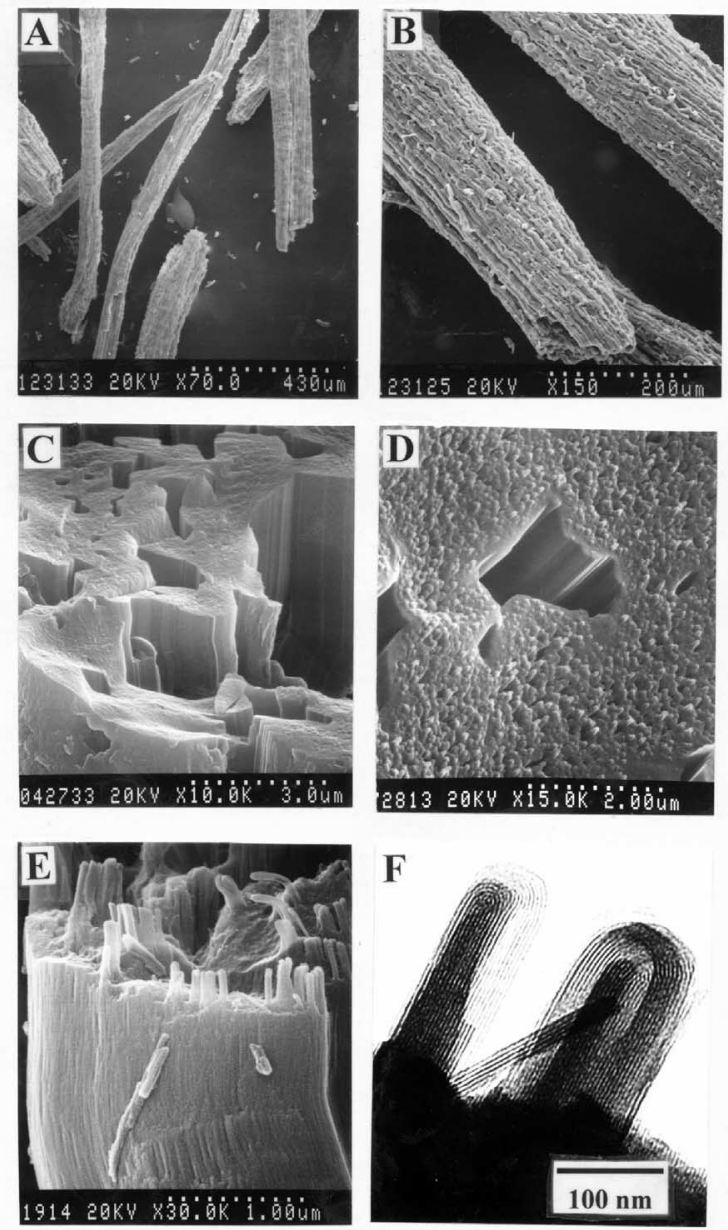

Fig 8. The SEM micrographs of the silica ropes prepared from $\mathrm{C}_{18}$ TMACl- $\mathrm{HNO}_{3}-\mathrm{TEOS}-\mathrm{H}_{2} \mathrm{O}$ compositions. Samples were subjected to ammonia hydrothermal treatment at different temperatures (A-C) $373 \mathrm{~K}$, (D) $403 \mathrm{~K}$ and (E) $423 \mathrm{~K}$. The aging time (two days) and the ammonia concentration $\left(\left[\mathrm{NH}_{4} \mathrm{OH}\right]=\right.$ $1.0 \mathrm{M}$ ) were kept constant during the hydrothermal treatment. The TEM micrographs (F) of the silica nanotubes was obtained directly from sample $(\mathrm{E})$.

backflow, which was induced by lattice expansion. It is also found that the average length of the silica nanotubes increases with the increasing extent of lattice expansion. The mechanism of such nanotubes extrusion is similar to myelin tubes typically originate from the water-induced lattice expansion of lamella phase. To the best of our knowledge, this is the first observation of the myelin-like silica nanotubes with hexagonal structure 
formed by the organic-inorganic hybrid hexagonal-structure matrix. Such extraordinary extrusion of silica nanotubes was also observed on the outer surface of the mesoporous silica with gyroidal and spherical morphology [22].

\section{Conclusions}

A comprehensive study of the effects of ammonia hydrothermal treatment on the enhancement of structural order, pore size distribution and thermal/hydrothermal stability of the acid-made materials while preserving its morphology has been made. This novel post-synthesis hydrothermal technique designed specifically for the acidmade mesoporous silica allows for the tailoring of structural property and morphology of the materials and hence should shed new light in the potential applications of the materials, for example, in chemical sensors, low dielectric film, optical and electronic devices.

Ammonia hydrothermal treatment at high temperature $(>373 \mathrm{~K})$ resulted in the expansion of pore size and extrusion of silica nanotubes from the mesochannels. The formation of the silica nanotubes, which arises from the expansion of the mesostructure during the hydrothermal treatment, should be helpful in understanding the elastic behavior of the hexagonal phase and transformation of interactions between inorganic framework and surfactant templates.

\section{Acknowledgements}

This work is supported by the Chinese Petroleum Corp. and Nation Science Council (NSC 882113-M-002-027). HPL is an Academia Sinica postdoctoral fellow.

\section{References}

[1] Q. Huo, S.I. Margoleses, U. Ciesla, P. Feng, D.E. Gier, P. Sieger, B.F.R. Leon, P.M. Petroff, F. Schueth, G.D. Stucky, Nature 368 (1994) 317.

[2] T. Kresge, M.E. Leonowicz, W.J. Roth, J.C. Vartuli, J.S. Beck, Nature 359 (1992) 710.

[3] H.P. Lin, C.Y. Mou, Science 273 (1996) 765.
[4] H.P. Lin, S. Cheng, C.Y. Mou, Chem. Mater. 10 (1998) 581.

[5] H.P. Lin, S. Cheng, C.Y. Mou, Micropor. Mater. 10 (1997) 111.

[6] H.P. Lin, Y.-R. Cheng, C.Y. Mou, Chem. Mater. 10 (1998) 3772.

[7] Q. Hou, S.I. Margoleses, U. Ciesla, P. Feng, D.E. Gier, P. Sieger, B.F.R. Leon, P.M. Petroff, F. Schueth, G.D. Stucky, Nature 368 (1994) 317.

[8] S. Schacht, Q. Huo, I.G. Voigtmartin, G.D. Stucky, F. Schueth, Science 273 (1996) 768.

[9] F. Marlow, M.D. McGehee, D. Zhao, B.F. Chmelka, G.D. Stucky, Adv. Mater. 11 (1999) 632.

[10] H.P. Lin, S.B. Liu, C.Y. Mou, C.Y. Tang, Chem. Commun. (1999) 583.

[11] Y. Lu, R. Gangull, C.A. Drewien, M.T. Anderson, C.J. Brinker, W. Gong, Y. Guo, H. Soyez, B. Dunn, M.H. Huang, J.I. Zink, Science 389 (1997) 364.

[12] M.A. Ogawa, Chem. Commun. (1996) 1149.

[13] D. Khushalani, A. Kuperman, G.A. Ozin, K. Tanaka, J. Garcés, M.M. Olken, N. Coombs, Adv. Mater. 7 (1995) 842.

[14] H. Yang, N. Coombs, G.A. Ozin, Nature 386 (1997) 692.

[15] P.T. Tanev, T.J. Pinnavaia, Science 267 (1995) 865.

[16] S.A. Bagshaw, S.A. Prouzet, T.J. Pinnavaia, Science 269 (1995) 1242.

[17] S.M. Yang, I. Sokolov, N. Coombs, C.T. Kresge, G.A. Ozin, Adv. Mater. 11 (1999) 1427.

[18] Q. Huo, S.I. Margoleses, U. Ciesla, D.G. Demuth, P. Feng, D.E. Gier, P. Sieger, B.F. Chmelka, F. Schuth, G.D. Stucky, Chem. Mater. 6 (1994) 1176.

[19] D. Zhao, Q. Huo, J. Feng, B.F. Chmelka, G.D. Stucky, J. Am. Chem. Soc. 120 (1998) 6024.

[20] Q. Huo, R. Leon, P.M. Petroff, G.D. Stucky, Science 268 (1995) 1324.

[21] H.P. Lin, C.Y. Mou, S.B. Liu, Chem. Lett. (1999) 1341.

[22] H.P. Lin, C.Y. Mou, S.B. Liu, Adv. Mater. 12 (2000) 103.

[23] A. Corma, Chem. Rev. 97 (1997) 2373.

[24] A. Sayari, P. Liu, M. Kruk, M. Jaroniec, Chem. Mater. 9 (1997) 2499

[25] D. Khushalani, A. Kuperman, G.A. Ozin, K. Tanaka, J. Garcés, M.M. Olken, N. Coombs, Adv. Mater. 7 (1995) 842.

[26] Q. Huo, D.I. Margolese, G.D. Stucky, Chem. Mater. 8 (1996) 1147.

[27] C.-F. Cheng, W. Zhou, D.H. Park, J. Klinowski, M. Hargreaves, L.F. Gladden, J. Chem. Soc., Faraday Trans. 93 (1997) 359.

[28] A. Corma, Q. Kan, M.T. Navarro, J. Perez-Pariente, F. Rey, Chem. Mater. 9 (1997) 2123.

[29] J. Feng, Q. Huo, P.M. Petroff, G.D. Stucky, Appl. Phys. Lett. 71 (1997) 1887.

[30] I. Sokolov, H. Yang, G.A. Ozin, C.T. Kresge, Adv. Mater. 11 (1999) 636.

[31] G.A. Ozin, H. Yang, N. Coombs, I. Sokolov, J. Mater. Chem. 8 (1998) 743. 